\title{
RELATIONS OF TOURISM AND HOTEL MANAGEMENT WITH RESPECT TO GDP GROWTH OF REPUBLIC OF SRPSKA
}

\author{
Momir Lazarević \\ University of East Sarajevo, Faculty of Economics Pale, Bosnia and Herzegovina
}

date of paper receipt:

20.09.2017.

Professional paper date of sending to review:

22.09.2017. date of review receipt:

27.09.2017.

\section{SUMMARY}

Tourism is the fastest growing and one of the most profitable industries in the world, with countless opportunities for the economic development of the regions.

One should not view tourism and hospitality as separate concepts, since one can neither exist nor can be sustained without the other.

A tourist, besides wanting to see and get to know the attractiveness of a place, wants to be offered a satisfactory level of basic (food, accommodation, transport) and additional (entertainment, recreation, shopping. . ) services which will certainly have an influence on his satisfaction and the desire to return.

If we don't turn to socially responsible behavior, we will lose the conditions for the development of tourism, and therefore a possible basis for social and economic prosperity as a result of such a sustainable tourism.

Globalisation also appears as a threat of uniformity of everything that surrounds us, because different societies, economies and cultures are increasingly intertwined and thus endanger the identity of one nation, its customs, folklore and overall cultural creativity.

Keywords: tourism, hospitality, tourist, globalisation

\section{INTRODUCTION}

Tourism is the fastest growing and one of the most profitable industries in the world, with countless opportunities for the economic development of regions. Current time of rapid changes requires restraint when it comes to making short-term, and especially long-term forecasts, since a large number of factors influence tourism events, so a realistic objective forward view is available only for a very short period of time. Tourism and hospitality should not be considered as separate concepts, since one can neither exist nor can be maintained without another. The tourist is primarily motivated to the travel by natural and cultural attractions, and in order to realise the journey, a tourist suprastracture is needed, among which the greatest influence have transport, food and accommodation. The tourist, in addition to the desire to see and get acquinted with the sights of a place, wants to be offered a satisfactory level of basic (food, accommodation, transport) and supplementary (entertainment, pastime, recreation, shopping ...) services that will certainly affect 
his satisfaction and desire to return again. The fact is that the increasing pollution of the Earth encourages tourists to "escape" from the polluted environment in an environmentally unpolluted areas where they can regain a peace of mind and find a place where they can recreate, rest and recharge their batteries. But the question is, in fact, how long we can still "rejoice" in ecologically untouched areas, because man has proved to be insufficiently responsible to preserve and help nature retain its original appearance. It's the same with cultural and historical heritage, monuments, temples, buildings of exceptional value for the history of a nation where little attention is paid to their preservation as a base for the development of tourism. If we do not turn to socially responsible behavior, we will lose the conditions for the development of tourism, and therefore a possible basis for social and economic prosperity which comes as a result of such a sustainable tourism.

Globalisation also appears as a danger of the uniformity in everything that surrounds us, as different societies, economies and cultures are increasingly intertwined, thereby endangering the identity of one nation, its customs, folklore and overall cultural creativity.

\section{GENERAL DETERMINERS OF TOURISM}

\section{CONCEPT OF TOURISM}

Tourism is an act of travel with recreation as a goal, as well as the use of various services related to this goal. The word "tourism" comes from the French word tour, which means travel, sightseeing, excursion.

A tourist is a person traveling at least eighty kilometers from a place of permanent residence for the purpose of recreation, as defined by the World Tourism Organisation.

A more comprehensive definition would be that tourism is a service industry consisting of a number of tangible and intangible elements. The tangible elements include:

- transport system - air, rail, road, water and more recent, space;

- hospitality services- accommodation, food and drinks, tours, souvenirs;

- related services - banking, insurance as well as safety and security.

Intangible elements include: rest and relaxation, culture, adventure, new and different experiences. According to the latest data from the World Tourism Organisation (WTO) ${ }^{1}$ in 2007, 898 million tourists participated in international tourism, and annual growth rate of $6.50 \%$ was recorded in the period from 1950 to 2007. The estimates of the World Tourism Organisation are that by 2020, the number of tourists participating in international tourism could amount to even 1.6 billion. $^{2}$

\section{CHARACTERISTICS OF TOURISM}

Basic characteristic of tourism are:

- diversity or heterogeneity (a large number of different services used by tourists);

- non-productive character of work (services provided can not be felt or stored before use);

- seasonal character of business (large concentration of tourists in a certain period of the year);

- a high degree of elasticity of demand (tourist demand is sensitive to the changing circumstances under which travels take place);

- inelasticity of the offer (tourist offer can not be changed in the short term).

1 http://media.unwto.org/

2 Ogorelc, A. (2001): International tourism (Mednarodni turizem), Economic and business faculty, University in Maribor, Maribor 


\section{DEFINITION OF TOURISM}

Universal definition of tourism: "Tourism is a set of relationships and phenomena occurring during travel and stay of foregners in a place if that stay does not mean permanent residence and is not linked to earning of profit." (Kurt Krapf and Walter Hunziker, 1942). This definition was recognised by the International Association of Experts for Tourism in 1971, although it only applies to foreign tourists.

\section{DEVELOPMENT OF TOURISM}

Tourism is a modern and massive socio-economic phenomena, but it is not new. Its development began at the same time three basic conditions for tourist movement were achieved:

free time - a time when it is possible to engage in tourism;

money - surplus of money needed for tourism;

infrastructure - facilities for providing hopsitality services to tourists.

The World Tourism Organisation predicts that international tourism will continue to grow at an annual rate of 4 percent. By 2020, Europe will remain the most popular tourist destination, but its share will fall from 60 percent in 1995 to 46 percent. The number of long-distance trips will grow slightly faster than the interregional, and by 2020 their share will increase from 18 percent in 1995 to 24 percent.

The share of space tourism should significantly increase in the first quarter of the 21 st century, although compared to traditional forms of tourism, the number of tourists in orbit will remain small until technologies like space lift do not make travel to space more profitable.

Over time, there have been setbacks in the development of tourism, among the latest is the one related to the 11th September 2001 attacks and terrorist threats to major tourist destinations such as Bali and European cities. Some of the famous tourist destinations, including Costa del Sol, the Balearic Islands and Cancun, have lost their popularity as tourist destinations, with a change in world tourism trends. In this context, excessive construction and destruction of the natural environment often associated with the traditional type of tourism ("sun and sea") can lead to significant degradation of tourism at that destination. Something like this happened to the famous Spanish resort of Costa Brava, which in the 1960s and the 70s was synonymous with this kind of tourism while the tourism industry of this region is facing a big crisis today.

When on 26th December 2004, tsunami caused by an earthquake in the Indian Ocean hit the coastal states, tens of thousands of people were killed, including a large number of tourists. This, together with the massive operation to cleaning the coastal area from the effects of the tsunami, has halted or significantly slowed down the development of tourism in this area.

\section{FIRST ORGANISED JOURNEY}

Wealthy people have always traveled to distant parts of the world to see glorious buildings or works of art, to learn new languages or to get acquainted with other cultures.

The first organised trip is connected to the name of Thomas Cook. He organised the transport of 570 tourists, who in 1841 were supposed to participate in a congress. That was the first time when a price discount was granted for a group trip. Cook suggested his service in the organisation and better utilisation of this means of transport to the railway in order to provide a favorable price for transportation. Thus Cook rented the whole composition and organised the transport of passengers. He provided tea and festive music for the participants, and the price of this arrangement per person was one shilling. Cook organised the first trip around the world in 1871 . The terms tourist and tourism were first officially used in 1937 by the League of Nations. Tourism is defined as traveling of people for 24 hours or longer in a country where they do not have permanent residence. 


\section{TYPES OF TOURISM}

According to the durating of the stay:

Overnight stay, in which tourists stays at least 3 consecutive nights at the accommodation facility or at the destination;

Excursions, whose duration is not longer than $24 \mathrm{~h}$;

Weekend tourism, most often includes staying at a destination from Friday afternoon to

Sunday evening.

According to the degree of mobility of tourists:

Stationary, it means the realisation of the entire annual holiday in one destination;

Mobile, includes continuous movement of tourists in the space.

According to the nationality of the tourists:

Domestic - it means visiting an attractive place located within the border of the country of residence,

Foreign (international) - includes travel of tourists outside the borders of their country of residence with the aim of visiting a tourist destination.

According to the spacial coverage:

Local - movement of tourists at the local level, most often excursions;

Regional - movement of tourists within one region (e.g. skiing, swimming, hunting), most often excursion and weekend tourism;

National - which does not require crossing the country's borders;

International - global scale movement that involves visiting attractive places that can not be found in the country of residence.

According to the age structure:

Children's - organised type of group trips for children under 14 years. Prerequisites for

this type of tourism are high quality of space and educated staff;

Youth - includes an organised type of group trips with a wide selection of sports,

educational and entertainment content;

Family - includes tourists between the ages of 18 and 60, yields the highest income but also has the most numerous requirements;

Pensioners' - consumer opportunities of this segment are growing. The working life is decreasing, and life expectency is increasing and this is the most homogeneous group of tourist demand.

According to the area where tourist travel takes place:

Seaside - the most attractive in the summer;

Mountain - that is attractive throughout the year, and especially in winter;

Thermal baths - as a rule it can be excursion and residence;

Lake - usually excursion or weekend tourism;

Rural - formed on the basis of cultural-historical identity, customs and tradition;

Urban- involves staying in a large urban environments with specific architecture, ambiance, cultural-historical values and events.

According to manner of the organisation:

Individual - implies a travel in one's own arrangement, according to one's own knowledge;

Organised - travel organised by a tourist agent and it's characterised by participants of

similar wishes and expectations;

Mixed - represents a travel in your own arrangement and use of information obtained by a travel agency or by purchasing tickets for an event;

According to the effect it has on balance of payments of a country:

Active - causes the overflow of funds from one country into tourist receptive country due to travel and stay of foreign citizens, which creates significant foreign exchange income; Passive - causes the overflow of funds from one country tourist into tourist receptive country due to travel and stay, which results in foreign exchange expenditures. 


\section{CURRENT STATE OF TOURISM AND CONSEQUENCES OF TOURISM DEVELOPMENT}

Tourism as a socio-economic phenomenon is in the process of continual and powerful changes. After the Second World War, primarily under the influence of an increase in living standards and leisure time, tourism grew into a mass phenomenon, taking into account the realised tourist traffic and the volume of activities in the tourist destination.

\section{MODERN SOCIAL TRENDS}

The achievement of ambitious growth rates of tourism trends will depend on the ability of the tourism to respond to the challenges of the expected changes in a society that will have an impact on tourist demand or so-called megatrends. There are eight modern megatrends:

Globalisation - the main characteristic is increasing intertwining of different societies, cultures and economies. Technological changes, further liberalisation in the trade of goods and services and increased mobility have made the whole world accessible.

Demographic changes - in 2020, about 20\% of the European population will be older than 65 . This part of the population will often have significant purchasing power and more free time for travel. In addition to the aging of the population, the number of households with one or two persons will increase.

Access to information - computer technology, the internet, internet browsers, mobile phones, global positioning systems (GPS) and digital television have deeply changed and are still changing the way in which we communicate, collect information and distribute products and services in the whole world.

Economy of experience - in an era where there is plenty of supply and where it is not always easy to differentiate products and services based on quality, consumers are increasingly looking for other factors on which they could base their choice. "Soft" features such as designs as well as the creative combination of products and services in a "total experience" are gaining importance.

Adjustment - the focus on "me" as a specific person will increase. Consumers are looking for "tailormade" solutions that suit their personality. Society can no longer be divided into homogeneous target groups, but it will be made of many different market niches.

Sustainability - concern over climate changes, environmental pollution and social well-being is transforming into increased demand of environmentally, socially and economically responsible consumption. This trend is strengthened by legislative initiatives aimed at encouraging consumers and companies to act more sustainably.

The health and wellness - the "sedentary" way of life of many people in developed countries has led to increased focus on health and wellness, as well as on free-time activities. The boundary between wellness and a lifestyle, on the one hand, and health care on the other, is becoming increasingly blurred.

Business models based on low cost - these business models are increasingly and successfully penetrating the market by bringing products and services to their most basic components, doing so along with more traditional business models.

Directing a large number of people to tourist destinations has led to certain ecological, cultural and social consequences that caused a review of the underlying basis of tourism. In order to reduce the negative effects of tourism, all costs must be covered by those participants who have directly or indirectly caused these costs. This can lead to the tourist product becoming uncompetitive in terms of the price, and there may also be difficulties in determining the cause of environmental pollution. There is also the opinion that by including social costs in price, the quality of products will be increased, and therefore the level of tourist experience in the destination will be greaeter and he will be ready to pay a higher price. 
Some of the important aspects of the negative effects of tourism development are:

Economic aspects - influence of the seasonal factors on tourism business, the effect of competition, high import dependence, which significantly reduces the realised foreign exchange inflow from tourism, the consequences of globalisation, the share of unqualified and poorly paid jobs in total employment, destruction of traditional forms of employment.

Socio-cultural aspect - the loss of cultural identity, the disappearance of the traditional system of values, the endangering of human rights, crime, prostitution.

Ecological aspects - emission of harmful gases by tourist means of transport, huge use of resources and waste production, water consumption, land consumption for tourist purposes.

To ensure that tourism contributes to overall development, it needs to be planned and managed in a manner that contributes to the quality of life of the local population and the protection of the natural and cultural environment. It also represents the basis of a sustainable development concept that is defined as a development that meets the needs of the current generation without compromising the ability of the next generation to meet its needs. Within the framework of sustainable development, economic and social development and environmental protection are considered to be interdependent and mutually supportive components, which form framework for directing efforts towards achieving a better quality of life for all people. Namely, that is responsible tourism, tourism friendly towards natural and cultural heritage. ${ }^{3}$ With the development of tourism, a number of positive economic functions are realised, such as the effect of tourism on the development of the tourism economy, the effect of tourism on the social product through invisible exports, the effect on employment that stimulates not only employment in tourism-related activities directly, but indirectly as well. Under the influence of tourism, poorly developed areas are beginning to develop more intensively because tourism becomes a driving force. Indirect effects that are not related only to basic tourist services (accommodation, food, transportation) such as on industry, construction, trade and agriculture are made by tourists simply staying in a tourist destination and consuming their products and thereby creating an additional market. Many places have their population number many times multiplied during the tourist season in comparison to off-season. ${ }^{4}$

\section{FACTORS NECESSARY FOR THE DEVELOPMENT OF TOURISM AND SEGMENTATION OF TOURISM}

For tourism to take place it is necessary to realise various factors related to demand, supply, and mediation of organisations that will facilitate the development of tourist traffic.

On the side of the demand, there must be driving factors which are divided into objective (rational) and subjective (irrational). Objective factors can be defined as created conditions in which a person lives and works, which, as such, determine his preferences and decisions, such as: population, industrialisation, urbanisation, financial resources, leisure time, cultural level of population, political and economic conditions in the country, income level. Subjective factors depend more on a man as an individual and his psychic and moral convictions, as well as on perception involving fashion, mood, habits, prestige, faith, love, snobbism.

On the offer side there are all the features important for one destination and precisely on them the level of tourist satisfaction with tourist products will depend. These factors include:

Attractive - they act as a driving factor for people looking for a vacation, entertainment, fun, recreation, they can be natural (hydrography, flora, fauna, relief) and anthropogenic (cultural and historical monuments, social events).

Communication - development of infrastructure and transport branches (roads, airports, railways). Receptive - activities that are directly and indirectly included in the provision of services to tourists (hotels, restaurants, post offices, telecommunications, shops, utilities).

3 Strategy for Tourism Development in Bosnia and Herzegovina for period 2008-2018.

4 http://www.bhtourism.ba/loc/ 
On the side of intermediaries, intermediary factors link the demand and offer to achieve social and economic effects, and those are: travel agencies, tour operators, social tourism organisations, national tourism organisations.

The tourist offer of receptive factors is diverse and it can be divided into basic (transport accommodation, food) and supplementary (entertainment, sports, passtime activites, recreation). The needs of tourists are varied and to reach the point of saturation toursits strive to try new experiences, get to know new areas, increase the quality of services provided more and more.

At given moment the offer can not respond to new tourist requests with new content, because the offer is not elastic in short term. Infrastructure and other tourist facilities require high investment and a longer period of time for construction.

Since tourism demand is heterogeneous and it is impossible to meet the needs of all tourists, it is necessary to divide the market and opt for one or more market segments whose needs can be met. The most common divisions are geographical, demographic and psychographic, and division according to the behavior in different situations. Geographical division helps us to determine the range of services according to the origin of tourists - cities, regions, and countries from which they come. Demographic division is useful because it determines nationality, age, sex, religion, income, occupation, education and it facilitates the choice of the target market. Psychographic division of the market implies the choice of a market based on personality, lifestyle, social class and perception. Division by behavior implies the expected behavior of tourists in accordance with the situation.

\section{CONCEPT OF HOTEL AND HOTEL INDUSTRY}

In order to tackle the concepts of hotel and hotel industry in the general sense, as well as an integral and inalienable part of the hospitality industry, it is necessary to make a small overview of what hospitality is as an essential factor in the existence and development of tourism as an economic activity, as we know it today. In that respect, it should be said that hospitality involves dealing with two types of activities, namely the preparation and sale of food and beverages in a specific way and the rental of furnished room for overnight stay. Therefore, hospitality is an economic activity of preparation, production and servicing of food, drinks and beverages and the provision of accommodation services. In practice, the catering sector is gravitating more towards the local population, while it is characteristic that the accommodation sector is primarily related to visitors from other areas and, in addition to offering accommodation services, it most frequently enables and provides food and beverage services as additional services. It is this fact that determines or defines, to a large extent, the hotel industry as an activity.

It should be noted, however, that when it comes to hotel industry, the provision of accommodation and catering services is not mandatory and that there are examples of such hotels where the food service is not implied. For example, this is the case with the so-called budget hotels or BB (bed and breakfast) hotels where the catering service is so rudimentary and it only includes a light continental breakfast. Precisely based on this fact, the rule that the accommodation and catering services are objectively separated and viewed as two different service packages remained till today. This means that you can use the hotel accommodation service separately from catering services in each hotel, and vice versa, which means that you do not have to be a hotel guest to use the food and beverage service within the hotel facility. Thus, the term BB (bed and breakfast), half board and full board were created. As we have seen it, the decisive activity of hotel industry is focused on the accommodation sector, but practice and theory confirm and appreciate the existence of hotel accommodation with or without food services. 


\section{DEFINITION OF HOTEL INDUSTRY}

Hotel industry is an activity that offers guests accommodation, food, drinks, recreation and a variety of other services. During the temporary stay in the hotel facilities at the selected destination, the hotel industry provides leisure and relaxation, helps business people make business contacts, hold seminars and various other professional, scientific and political gatherings, creating conditions for constructive work, allowing tourists to get acquainted with natural attractions and cultural monuments.

Hotels provide accommodation services in rooms, but also in hotel suites. As a rule, hotels offer double rooms, they can also offer single rooms, and often provide the possibility of using an additional or auxiliary or children's bed. However, in any case, hotels rent rooms, beds and the hotel's "unit of measurement" for the purpose of determining the business results is a rented room and not an overnight stay.

Hotel industry is an activity that is a result of relatively short production processes with a variety of services and products that satisfy the wishes and needs of consumers. Although a part of the business activities have the character of material production (supply of food and beverages), hotel industry is essentially determined by the circular character.

\section{SPECIFIC FEATURES OF HOTEL INDUSTRY}

- In hotel facilities, consumers are offered accommodation, food and drinks, other outside services;

- Services must be constantly adapted to the requirements of guests;

- Direct contact with the guest is necessary because the services can not be provided when there are no guests;

- Employees must always be ready to provide services;

- Working time is "flexible";

- It is difficult to plan and coordinate the needs of employees with occupancy of the capacity;

- Uneven business intensity during the day and year determines special working conditions

- seasonal work, with long standing, walking or working at high temperatures.

When it comes to hotels as the most well-known and most widespread facilities for providing accommodation services, it should be said that many authors emphasize the specialty of services in hotels, which primarily relate to the high quality of accommodation services, personnel and interior design, as well as ability to meet modern requirements of travelers. In this sense, a hotel has to respond to certain habits of travelers, such as high class of living and alimentation, and in this regard, provide adequate quality of service, professionalism and modern management of the facility. In order to separate the hotel as a special type of hospitality facility for accommodation and differentiate it from other facilities that nominally provide the same type of service, International Association of Hotel General Managers reached a decision in 1926 on the minimum common characteristics of each object that wishes to be called hotel. These common features relate to: organisation and management which function to provide high quality of accommodation, accommodation and food as respective activities, architecture and design of space in and around the facility, empasised sanitary and hygienic safety and fire protection, interior design of rooms for accommodation with the existence of an appropriate number common rooms and sanitary facilities outside of the commercial rooms, appropriate surface area of the rooms and their interior fitting, service and technical personnel and fitting of the kitchen unit according to modern food, technical, sanitary and hygienic standards.

When it comes to the capacity of the hotel, which alludes to its size, it can be said that there are several such divisions. The hotels are mainly divided on small, medium and large hotels, that is, hotels with small, medium and large capacities. In some divisions, the medium capacity can be 
defined through two determinants, as average and above average. The essence is clear, but the problem arises, however, with defining terms small and large, which are drastically different from one author to the next, that is, they depend on the continent from which they come from. In that sense, European authors like Dukas from Great Britain think that small hotels have up to 25 rooms and large hotels have a capacity of over 300 rooms. On the other hand, American authors Casavana and Brooks move the borders up, so hotels with a smaller capacity have up to 150 rooms, while large-capacity hotels have over 600 rooms. Also, the experience has shown the existence of the so-called mega hotels whose capacity exceeds 1000 rooms. Such hotels are characteristic for the world's major metropolises, the most famous entertainment centres and the world's greatest summer resorts.

Another important feature of the hotel as a hospitality facility for accommodation and hotel industry as a business activity with constant development is the typification of the hotel. Typification is the process of differentiating certain phenomena within the same type of object. The separation of certain types of hotels is an integral part of the development of hotel activities, but also reflects the degree of development of this activity. This means that the existence of a number of different types and subtypes of hotels indicates a higher degree of development of hotel industry as an economic activity. The process of differentiation, i.e. typification within the hospitality industry takes place under the influence of a large number of different external factors. The two most important factors based on which hotels can be differentiated into dozens of special types of are: location on one hand and reason of visit, assortment of services and category of consumers on the other. In that sense, the location factor differentiates the following types of hotels: seaside, mountain, spa, city, transit. When it comes to the other mentioned factor, which primarily refers to the motive of the visit, it should be said that it caused the following division: resort, business, conference, convention, casino, sport and thematic hotels. Therefore, it is clear that the process of differenciating certain types of hotel facilities is under the influence of a number of different factors, whereby the forms of occurrence and intensity of effect are variable categories, which are changed in accordance with the development and improvement of hotel activities, human society as a whole and a man as an individual and consumer, that is, user of those services. It turns out that it is not possible to talk about complete divisions, but in a series of cases, hotels are border types dominated by two or even three factors. In this sense, the hotel can be located at the seaside, be themed and be oriented towards casino games. In this regard, a large number of objects representing combinations of different types exist, precisely because of the different criteria are simultaneously used for differentiation. The most important application of specialisation, that is, typification of the hotel is in defining and developing a business strategy. In a broader sense, specialisation implies directing attention to a precisely defined group of users of services, that is, consumers, so the business strategy in addition to directing activities into one of the specific market niches implies the establishment of basic guidelines in the field of marketing and management of the hotel.

\section{ORGANISATIONAL STRUCTURE OF HOTELS}

Basic elelments of organisational structure are:

- management

- makes decisions, that is, manages the business activities of the hotel;

- accommodation department (room division)

- reception - receives, allocates rooms, sends off guests and charges services;

- porters' service, performs work related to arrival, stay and departure of the guest;

- housekeeping department, takes care of cleanliness of rooms and common areas;

- catering department (food and beverage)

- kitchen - production unit for preparation of meals and sweets;

- restaurant - sale unit for sale of food and drink; 
- aperitif bar - production and sales unit for preparing and serving drinks and beverages;

- recreation department

- combines recreational, sporting, entertainment and cultural hotel facilities;

- sales and marketing department

- carries out activities of sale and marketing of hotel facilities;

- controlling and finance department

- collects, processes and presents data, that is, information on hotel business and performs other financial activities;

- technical department (maintenance)

- takes care of the correct working of the equipment and the devices, that is, the maintenance of the hotel.

\section{WORKING OF HOTEL}

In order for the hotel to operate successfully and achieve good results, it is necessary for the consumer to be the starting point of any business operation. It is necessary to carry out certain research and analyses in order to determine the segments for which its business is intended. This will affect the way the hotel will be equipped and arranged, the contents that it should have, and from there, also the appropriate organisation and all economic, technological and other key factors of the entire business acitivities of the facility. One of the basic goals, of other companies as well is the creation of loyal customers. This can be accomplished by a long-term process involving the creation of such a relationship which starts with the arrival of the guest, provision of services that exceed the level of his expectation, efficiency, quick delivery and above all a friendly demeanour of each employee, that is, responding appropriately in accordance with the situation. This relationship between the hotel and the guest does not end with the departure of a guest from the hotel, but they also strives to keep in contact after completion of the services via telephone, e-mail and other forms of communication so that the guest is informed about special offers, bonuses, complementary offers and other benefits in order to create a loyal customer. Type, category, size and location of the facility will depend on the market segment that it wants to enter as well as on the market potential and demand.

By implementing the categorisation of hospitality facilities setting of standards is done, which significantly affects the quality of services and competitive position in relation to other hotels. The categorisation increases consumer awareness of the quality and scope of services provided by the hotel, and facilitates the control of business operations.

The business of the hotel depends on its location to a large degree. The location dictates the type, category and size of the object, as well as the market segment whose needs are to be met. When choosing a site, one should take into account its attractiveness for certain segments, the connection with the suppliers of products which significantly affects the costs of the company, but also easy accessibility of the labour. Certainly larger cities have better predispositions to attract suppliers and high-quality workforce compared to smaller areas where business networks are not very developed, where educational programs are not strong, and the quality of life is much lower in terms of the availability of certain products and services whose proximity is especially important for facilitating business activities. If the hotel wants to opt for a segment of business guests, it should be located in towns as close to the city centre as possible. If tourists travel for tourist reasons: vacation, recreation, fun, entertainment, the hotel should be located in a place that will best meet the expectations of guests such as mountains, coasts or other attractive locations. In the transit area, hotels should be located next to the main roads. Each hotel should pay great attention to building a recognisable image that will separate it from the competition in a particular area. The image depends on the perception of the guest and the manner others see us. In order to maintain a good image and achieve better, it is necessary to constantly research and analyse the market to 
find out ones weak points and what guests are thinking. The image should differentiate one from the competitors and this is achieved through price, quality, wide range of services, good staff and various different ways. By creating a brand in a particular business activity, customer confidence and buying security increases, meaning that the customer, regardless of the high substituability of products and services, will always choose you, because he knows that your services are verifiably good, and the customer primarily wants to reduce the risk when buying, he want to achieve or exceed the expected level of benefits.

Staff plays an important role in the provision of services, since the quality of service and customer satisfaction will depend on the employees. It is a fact is that living human contact with the guest can not be replaced with any machines, appliances or devices. Therefore, due attention should be paid to recruitment, selection, training and grooming, inspection of work, motivation and encouragement of the highest quality of work by different methods. Some of the possible incentives can be pay raises, prize-winning trips for achieving business results that are above average, the possibility of taking days off, organised transportation, commendations, banquets. In order to provide quality services, first it is necessary to establish a relationship with employees and then with customers because there are no satisfied guests without satisfied employees.

The sale of hotel and other tourist services is often done well before their provision and consumption. It is done through a reservation system or contracting with tour operators and other partners before the arrival of guests to the hotel. The sale of hotel services can be direct and indirect. For direct sales, there are no intermediaries, these services are usually not sold on a flat basis, but only to individual guests. The benefits of direct sales are:

Establishes and maintains direct contacts with consumers;

It exercises control over placement in a situation where intermediaries do not show sufficient interest in increasing sales or they are neglecting certain parts and market segments when offering service packages;

It overcomes the possible lack of efficient and well-organised intermediaries;

It strives to reduce costs by creating its own sales organisation and thus make it more competitive. The basic feature of indirect sales is the existence of an intermediary in sales. The function of intermediaries-tour operators and travel agencies is based on the following advantages:

For consumers - they can choose and compare different tourist services, they can purchase a complex tourist product that includes all elements at once, they can get relevant information in place of residence;

For hoteliers - they don't have to offer their services themselves and need fewer sales facilities, sale is made in much wider area, brokers are qualified and well-trained for sale, their role as intermediaries saves money and time of the producers, which enables the lowering of prices.

The development of information and communication technology has led to major changes in the sale of hotel and tourist services in general. Capacity management, productivity optimisation, coming closer to the customers, partnership development and many other phenomena have lost their traditional outlook and have a new one in contemporary conditions. 


\section{CONCLUSION}

Based on everything mentioned above in relation to tourism and hotel management, one concludes that both areas are strongly interdependent, they can not exist one without another. They are in the process of constant and dynamic changes dictated by the conditions in which they operate and such environment requires continuous monitoring of the situation and adjustment. Companies can influence some of those changes by undertaking the best actions in the given situations. They can influence customers, suppliers, distributors and competition. They have to adapt to the political, economic, technological and social environment because they can not be or can be only marginally influenced on. The occurrence of mass tourism has caused numerous negative ecological and social consequences. A large number of tourists have caused numerous environmental pollution with different types of transport, the construction of tourist suprastructure destroys nature and landscape, flora and fauna also suffer great consequences. The environmental resources are precisely the base on which certain forms of tourism develop and their destruction would not only have an impact on tourism, but also on the survival of the man who lives and exists thanks to them. Attractive anthropogenic resources are also endangered: monuments, buildings, temples, objects of importance for the history of man, because mass tourism, which does not care enough about such values, destroys and defiles them. Populated areas in which tourism develops also suffer the consequences of such mass tourism as the number of tourists threatens their conditions of life by creating crowds, rising food prices and directing the structure of the economy towards the development of tourism, ignoring other branches of the economy. The culture of that population is also endangered because tourists come from other areas and bring with them the habits and customs of their permanent place of residence that are different from the ones at tourist destination. The tourist offer adapts to the tourists in order to maximally meet their needs. These effects have a bad influence on the culture and identity of a nation. Due to all the negative consequences of mass tourism, the idea is to develop alternative, sustainable tourism that will be socially responsible to environment and will strive to use resources rationally in order to preserve them and at the same time meet economic criteria. Hotels that want to do business successfully will need to improve the quality of their products and services and strive to to be superior in comparison to the competition. They can achieve this by selecting one or more segments and matching their offer with the needs of those segments. Consumers are a changeable category, always ready to try and experience something new, so researching their needs is a continuous process that alone can bring hotel success. Hotels should seek to create and maintain a good image that will differ from the competition. To achieve this, it is necessary to determine the strengths and weaknesses, threats and opportunities, and compare them with competitors. Based on this, we can best see what are our strengths and how we can be different. It is necessary to establish a harmonious internal organisation which will affect not only the satisfaction of the guests, but also the employees. 


\section{LITERATURE}

1. Bataveljic, D, (2016), Significance and Influence of Tourism on Economy of Republic of Serbia (Značaj i uticaj turizma na privredu Republike Srbije)

2. Blagojevic, S, (2002), Ecological Trends in Modern Tourism (Ekološki trendovi u savremenom turizmu), Turizam 6/2002, Novi Sad

3. Cooper C., Fletcher J., Fyall A., Gilbert D., Wanhill S., (2005), Tourism Principles and Practice, (Third edition), Pearson Education Limited, Harlow, England;

4. Hall C.M. (2000), Tourism planning; Policies, Processes and Relationships, Prentice Hall, Harlow;

5. Hansruedi Müller, Tourism and Ecology (Tourismus und Ökologie ), 2003, Vienna

6. Jelusic M., Vujovic S. (2002), Who Decides in Budva (Ko odlučuje u Budvi), Argonaut, Budva;

7. Ogorelc, A. (2001): International Tourism (Mednarodni turizem), Economic and business faculty, University in Maribor, Maribor

8. Masterplan, Strategy for Development of Tourism of Montenegro by 2020

9. Magas D., Management of Tourist Organisation and Destination (Menadžment turističke organizacije i destinacije), (2003) Faculty for Tourist and Hospitality Management, Adamic d.o.o., Opatija;

10. Marinoski, N., (1998) Transformation of Space under Influence of Tourism (Transformacija prostora pod uticajem turizma), Turizam, Novi Sad

11. Nigel E., Campbell D. and Stonehouse G (2003), Strategic Management for Travel and Tourism, Butterworth-Heinemann, Oxford;

12. Pasinovic M. Milenko, Management of Natural and Cultural Resources (Menadžment prirodnih i kulturnih resursa),(2006) MTS- Bar, University Mediteran, Podgorica, Bar;

13. Collection of Works from the Scientific Conference in Cetinje, 23-24 May 2002 (2004), Tourism of Montenegro in the Second Half of XX Century

14. World Tourism Organization, www.unwto.org

15. http://turizamrs.org/milici/

16. http://media.unwto.org/

17. http://www.visitmycountry.net/bosnia_herzegovina/bh/

18. http://www.bhtourism.ba/loc/

19. http://www.ruralextension.org/doc/Strategija\%20razvoja\%20turizma\%20FBIH\%202008$2018 \% 20(2008) . p d f$ 